\title{
Exploitation Strategies of Cabin and Galley Thermal Dynamics
}

\author{
Author, co-author (Do NOT enter this information. It will be pulled from participant tab in \\ MyTechZone) \\ Affiliation (Do NOT enter this information. It will be pulled from participant tab in MyTechZone)
}

\begin{abstract}
The thermal inertia of aircraft cabins and galleys is significant for commercial aircraft. The aircraft cabin is controlled by the Environment Control System (ECS) to reach, among other targets, a prescribed temperature. By allowing a temperature band of $\pm 2 \mathrm{~K}$ instead of a fixed temperature, it is possible to use this thermal dynamic of the cabin as energy storage. This storage can then be used to reduce electrical peak power, increase efficiency of the ECS, reduce thermal cooling peak power, or reduce engine offtake if it is costly or not sufficiently available. In the same way, also the aircraft galleys can be exploited. Since ECS and galleys are among the largest consumers of electrical power or bleed air, there is a large potential on improving energy efficiency or reducing system mass to reduce fuel consumption of aircraft. This paper investigates different exploitation strategies of cabin and galley dynamics using modelling and simulation. Modelica models of the thermal and the electrical system are used to assess and compare these different strategies. Potential impacts on passenger comfort are discussed. Additionally, the gained performance is compared to more conventional storage elements like electrical batteries. Finally, the potential of fuel reduction will be quantified using a reference aircraft model and the optimal strategy is selected.
\end{abstract}

\section{Introduction}

The reduction of aircraft emissions is a major goal for current commercial aircraft design [1]. Increasing the efficiency and reducing the mass of aircraft systems may contribute to this objective. This has led to the development of More Electric Aircraft (MEA) in the past $[2,3]$. Expected benefits of MEA are an increased energy efficiency of the systems, less maintenance and increased reliability. In recent aircraft developments, MEA were more efficient, but tended to be heavier than their conventional counterparts [2]. The added mass can even cause a higher fuel consumption of a MEA compared to a conventional aircraft. Hence, the reduction of system mass is a key enabling factor for future aircraft developments.

To reach this goal, several investigations of intelligent energy management functions have been performed for the electrical and thermal system in the past $[6,7,8,15]$. These functions allow for an increase in overall energy efficiency and a reduced ram air drag by providing optimal control signals. Moreover, due to the model-based approach, an integrated design of the control functions together with the energy system allows a significant reduction of system size and hence weight.

Page 1 of 6
This type of energy management functions can also use energy storage elements like an electrical battery to e.g. reduce power peaks. The usage of batteries for this purpose sounds promising, but a sufficient amount of batteries may add significant weight to the aircraft due to their relatively low energy density (compared with fuel). On the other side, significant energy storage elements are already available onboard an aircraft, in the form of thermal inertias. The thermal inertia of aircraft cabins and galleys is significant for commercial aircraft. Allowing a temperature band of $\pm 2 \mathrm{~K}$ around the prescribed temperature, it is possible to use the cabin dynamics as energy storage. This storage can then be used to reduce electrical peak power, increase efficiency of ECS, reduce thermal cooling peak power, or reduce engine offtake when it is costly or not sufficiently available. In the same way, also the aircraft galleys can be exploited. Since ECS and galleys are among the largest consumers of electrical power or bleed air, there is a large potential to improve energy efficiency or reduce system mass to further reduce fuel consumption of aircraft.

\section{State of the art}

The exploitation of cabin and galley thermal dynamics in principle is not a new idea. A method that exploits large responding times of aircraft galleys is claimed in [10]. The reduction of power peaks is realized via time-sharing, power-sharing and peak compression. Time-sharing alternately switches loads on and off. Power sharing reduces the consumption of a load in a fashion that a second load can be switched on for a dedicated time. Peak compression avoids the power-on of two loads at the same time. For this purpose, predefined procedures are determined for a set of cases to reduce power peaks by keeping full availability of the electrical devices.

A more flexible approach can be found in [11]. Here the electrical system is divided into a primary load system having a proprietary controller and a secondary load system (e.g. an ECS) controlled by a conventional electrical load management (ELM). Depending on cabin temperature and further parameters the ECS controller can decide if and to what extent the power can be reduced as shown in Figure 1. If the maximum power threshold of the generator is exceeded or is expected to be exceeded, the power consumption of the ECS can be reduced continuously by its own controller. The ECS controller and ELM communicate with each other. If a reduction of ECS is no longer possible, the ELM cuts loads. Thus, this approach prevents power peaks without any impact on the availability of the loads using the cabin dynamics as much as possible. 


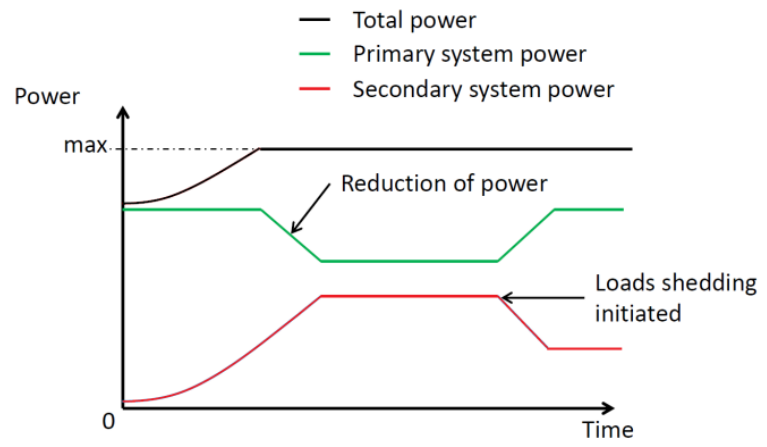

Figure 1: Controlling electrical power of primary and secondary system as done in [11]

\section{Contribution of this Paper}

This paper investigates different exploitation strategies of cabin and galley dynamics, not only for the electrical system but also for the thermal system.

1. Strategy 1 - Exploit cabin inertia to increase energy efficiency of ECS for a mission.

2. Strategy 2 - Reduce thermal peak loads to reduce the sizing of cooling system and ECS.

3. Strategy 3 - Reduction of electrical peak power to downsize the electrical system.

We assess and compare these different strategies using basic calculations and, where suitable, Modelica models [5] of the cabin and galley dynamics as well as models of the thermal and the electrical system.

To demonstrate and assess the benefits, we structure the paper as follows. First, the cabin and galley thermal dynamics are investigated and quantified. Then, the three different strategies will be demonstrated. Furthermore, we discuss and compare these different strategies to assess its impact on aircraft emissions and passenger comfort. Additionally, the gained performance will be compared to more conventional storage elements like electrical batteries. Finally, the optimal strategy will be selected.

\section{Cabin and Galley Thermal Dynamics}

The thermal dynamics of the cabin are dominated by the convective heat-flows of air-circulation. Heat radiation and conductance also play a significant role, but for short-term dynamics, they can be neglected in a first approximation. Instead these effects are simply collectively modelled by a constant thermal load $\mathrm{P}_{\text {load }}$ on the cabin air. The convection rate is also almost independent from the supply of thermal energy, since the air is actively ventilated and mixed. Even if less cooling (or heating) power shall be supplied, pressurization, fresh air-supply and also the air recirculation need to be maintained at all times. The pressure of the cabin is controlled by the pressure release valves at the rear of the cabin that release air to the outer environment.

Regulations prescribe a fresh air supply of 0.55 lbs per passenger per minute [14] or $4.16 \mathrm{~g} / \mathrm{s}$ in SI units. Typically one of two packs alone must be able to supply this amount at least when switched to a mode of ca. $120 \%$ of its nominal power [13]. The actual fresh-air supply with two packs at $100 \%$ of operation would then correspond to Page 2 of 6
$6.93 \mathrm{~g} / \mathrm{s}$ per passenger or ca. $\mathrm{m}_{\mathrm{flow}}=1.4 \mathrm{~kg} / \mathrm{s}$ for a plane with 200 passengers. This corresponds to the common practice to supply more fresh air than regulations prescribe. In practice, even higher numbers are likely.

Figure 2 illustrates the typical flow of air in a passenger aircraft. The fresh air from the two packs is supplied to a chamber where it is mixed with the recirculation air that is streaming from the cabin area into the cargo area through the recirculation filters and fans. The chamber is hence called mixer and its air content must be cold enough to meet the thermal demand of the coldest cabin zone in the aircraft. For the other zones, the air can then be reheated by supplying hot trim air and/or by electrical heating wires. Typically warmer air is supplied to the front part than to the rear part.

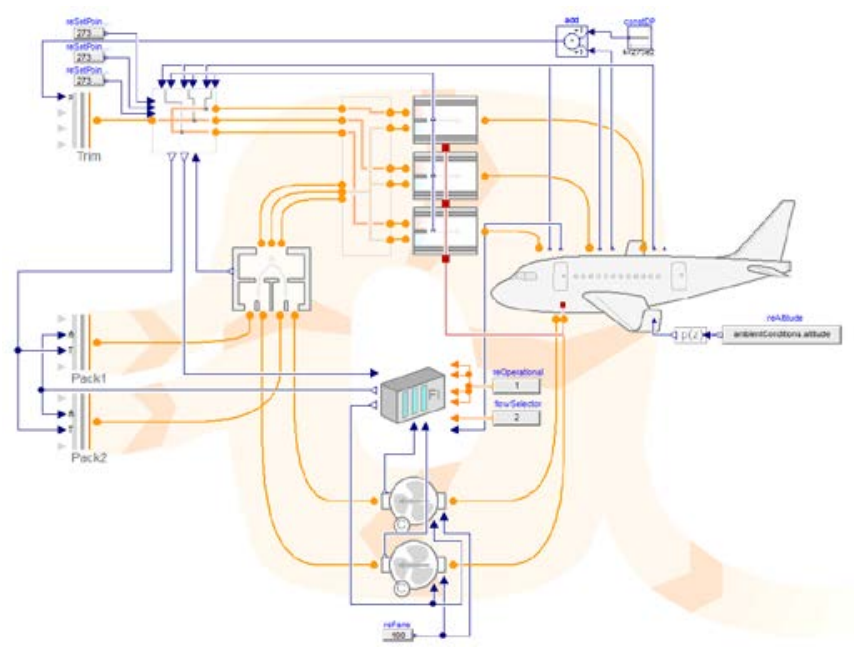

Figure 2: Model diagram of the air circulation within a typical passenger aircraft

Given this configuration, it becomes evident that the time constant of the thermal dynamics are dominated by the ratio between the mass flow rate of instreaming fresh-air from the packs and the total recirculated mass of air. For a 200 passenger aircraft we can assume a volume for flight-deck and cabin of roughly $220 \mathrm{~m}^{3} .80 \%$ of this volume $\left(180 \mathrm{~m}^{3}\right)$ can roughly be attributed to air. The mixer volume is comparably small and the underfloor volume is typically blocked by cargo-containers. Hence we assume an additional $20 \mathrm{~m}^{3}$ leading to the convenient figure of $200 \mathrm{~m}^{3}$ for the total recirculated volume (as a lower estimate). At typical cruising altitude with a cabin pressure of 0.85 bar this corresponds also to $\mathrm{M}_{\mathrm{air}, \mathrm{cab}}=200 \mathrm{~kg}$ of air.

These $200 \mathrm{~kg}$ of air then represents a storage unit of roughly $400 \mathrm{~kJ}$ (or $\sim 100 \mathrm{Wh}$ ) of thermal energy if we take into account the $2 \mathrm{~K}$ bandwidth for comfort. Compared to the power of the ECS (hundreds of $\mathrm{kW}$ ) the actual storage capacity is hence quite small. Yet, the thermal capacity may be useful to compensate for temporary load peaks. To understand the temporary dynamics, we can assume an ideal mixing with fresh inlet air.

The ideal mixing law then yields an equation for the gradient of the mean specific enthalpy of the cabin:

$\mathrm{dh}_{\mathrm{cab}} / \mathrm{dt} \cdot \mathrm{M}_{\mathrm{air}, \mathrm{cab}}=\left(\mathrm{h}_{\underline{\mathrm{fresh}}}-\mathrm{h}_{\mathrm{cab}}\right) \cdot \mathrm{m}_{\text {flow }}+\mathrm{P}_{\text {load }}$

For small temperature differences and constant pressure this law can be directly transferred from specific enthalpy to temperature by 
dividing with the specific heat capacity $\mathrm{C}_{\mathrm{p}}$ of the approximate thermodynamic state:

$\mathrm{dT}_{\text {cab }} / \mathrm{dt} \cdot \mathrm{M}_{\text {air,cab }}=\left(\mathrm{T}_{\text {fresh }}-\mathrm{T}_{\text {cab }}\right) \cdot \mathrm{m}_{\text {flow }}+\mathrm{P}_{\text {load }} / \mathrm{C}_{\mathrm{p}}$

For a control engineer, this corresponds to a first order system with the time constant $\mathrm{T}=\mathrm{M}_{\mathrm{air}, \mathrm{cab}} / \mathrm{m}_{\mathrm{flow}}$ which, in our example, corresponds to 142 seconds or roughly 2 minutes. From the perspective of the electrical system this is a very long time constant, making the cabin an attractive element for intermediate energy storage.

Figure 3 illustrates this behavior for different steps of the fresh-air temperature. This LTI model does extend the equation from before by now taking into account two more time constants for seats and lining ( 1000s) and the cabin wall (1-2 h). These additional time constants imply that at least for smaller changes of the inlet temperature, the comfort bandwidth can be uphold longer since the heat capacity of seat, linings, and walls dampen the effects.

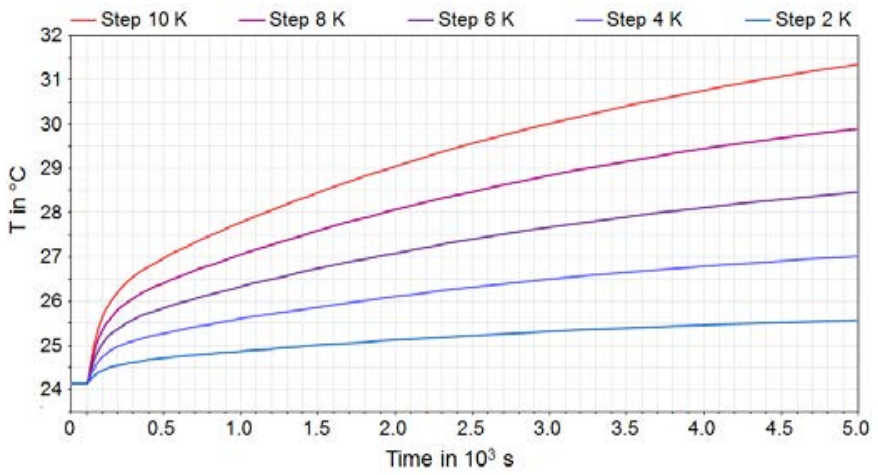

Figure 3: LTI behavior of cabin temperature

The galleys contain another electrical consumer with a relatively large time constant. With several $\mathrm{kW}$ of peak power, these represent another significant electrical consumer. For the heating of food a certain amount of energy must be supplied. The time taken to provide this energy is typically a few minutes but can however be easily stretched by $20 \%$ without impairing operation much. Within this $20 \%$ bandwidth of time and within the power limits, it can be regarded as almost irrelevant how exactly the required energy is provided over time. The thermal inertia of the insulated oven is expected to flatten this out. Hence the full power of a galley oven can be temporarily shed, making this a very attractive load for an energy management routine. In practice even partial shedding may be sufficient and enforced to ensure the quality of first-class food preparation.

\section{Strategy 1 - Increase Efficiency of ECS}

Thermal Management Functions (TMF) as developed in [15] are capable of calculating optimized control signals in real-time for thermal management systems by using model-based system knowledge. This can be either a physical model of the system or a data record generated from this model. The TMF provides control signals to the air and vapor cycle which are possible sources of cooling power, as well as load reduction or shedding signals. To determine an optimal cooling split between air cycle, vapor cycle, and its associated ram air channels, trade factors are being used to make electrical power offtake and ram air usage (i.e. drag) comparable, since both have influence on fuel consumption.
The considered Thermal Management Architecture (TMA) encompasses air cycle machines, ram air channels, circulation and distribution of air flow, vapor compression cycles, cooling loops, as well as alternative heat sinks like skin heat exchangers [4]. Together with highly integrated and complex TMAs, there is an increased degree of freedom in controlling the system. Optimal controller signals provided by a TMF are essential to improve system efficiency and to reduce system weight. A TMF can optimize control signals to the different sources of cooling power to reduce power offtake from the engines and ram air usage, which results in lower drag. The fuel consumption caused by the ECS containing different compressors, ram air channels, vapor cycle, strongly depends on the environmental conditions (temperature, pressure, humidity) and the flight phase. The TMF needs to know the system performance of the air cycle machine and the vapor compression cycle at the current operation point and environmental conditions. This system knowledge is gained from the TMA model. The model is already available and contains detailed system knowledge under all operational and environmental conditions.

In [15], the TMF was able to gain significant benefits for the selected TMA. For the selected mission, a gain of up to $10 \%$ reduction of fuel consumption for the entire TMA was achieved (caused by induced drag and electrical power offtake). This has been demonstrated by modelling and simulation in Modelica as shown in Figure 4.

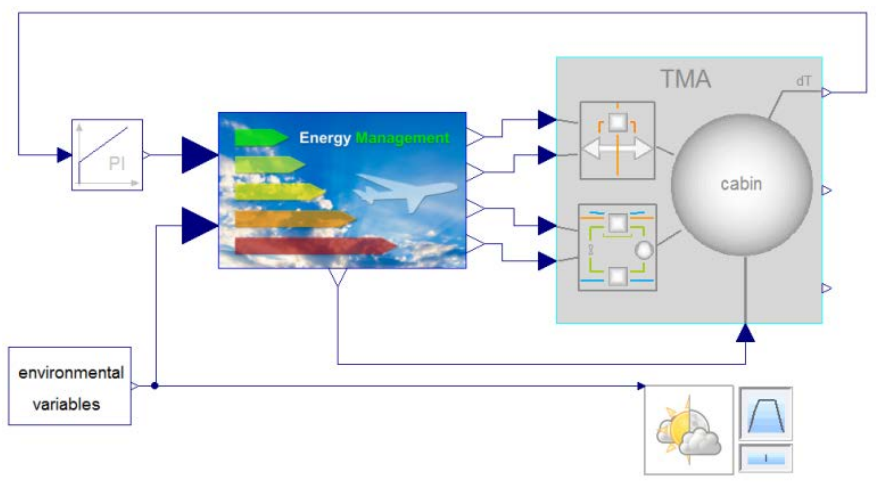

Figure 4: TMF integrated with TMA model as in [15].

The idea for strategy 1 is, to further increase the benefits gained from the TMF by exploiting the cabin dynamics. Hence, one can use the cabin inertia to increase cooling during phases where this is cheap and decrease cooling where it is expensive. Figure 5 illustrates the relative impact on fuel consumption of additional cooling or of reduction of cooling for an electrical TMA according to [15].

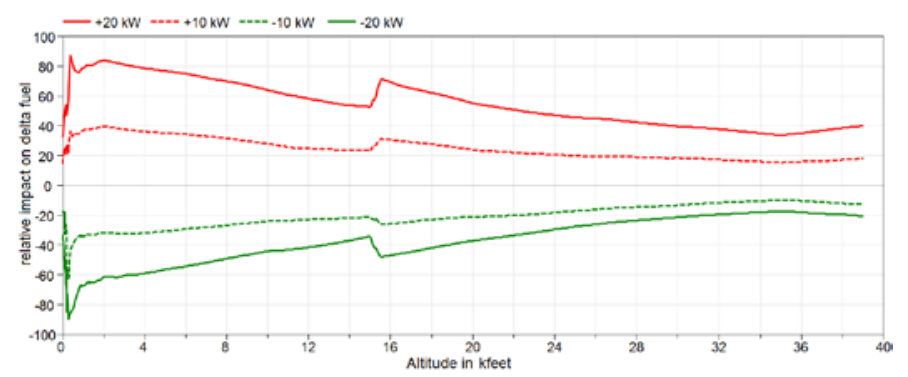

Figure 5: relative impact on fuel consumption for different additional cooling powers. Baseline is the cooling demand for ISA Day.

Page 3 of 6 
Hence, this figure gives basic information on possible dynamic TMFstrategies for a mission to further increase efficiency of ECS. Firstly, additional cooling causes higher deltas of power equivalent than reducing cooling power for the same amount. Secondly, costs for cooling on ground and at high altitude are lower than for start, climb, approach and landing. Finally, one can notice some peaks around 1000 feet and 15000 feet. They mainly result from the implementation of local controllers, like the ram air or pack controller. These peaks should not be considered for a dynamic TMF.

Due to these statements, it is very probable that the TMF cannot significantly improve the total power equivalent by using the cabin dynamics. Additionally, in different optimization runs no improvement could be achieved. Nevertheless, this statements needs to be reassessed for different architectures and different operating conditions. But it is probable that the benefits of using the cabin dynamics for this purpose are too small and that there are better ways of exploiting them.

\section{Strategy 2 - Reduce Thermal Peak Loads}

The ECS system weight is strongly dependent on the maximum performance it has to achieve. This can easily be seen when looking at a single heat exchanger as a part of the air conditioning pack: If the heat conducting surface of a heat exchanger is increased, it can transfer heat more effectively. On the other hand, the mass of the heat exchanger goes up.

For advanced ECS architectures, there are multiple degrees of freedom, when it comes to the question of how a specific situation is being handled: If the pack discharge temperature is too high, the ram air channel inlet can be opened further, increasing the cooling air mass flow, thereby increasing the temperature difference in the heat exchangers and decreasing the pack discharge temperature.

Alternatively, more electrical power can be given to the vapor cycle, having a similar effect. In the scope of this strategy, we are interested in the reduction of thermal peak loads. Therefore we assume that all degrees of freedom in the ECS are already exhausted.

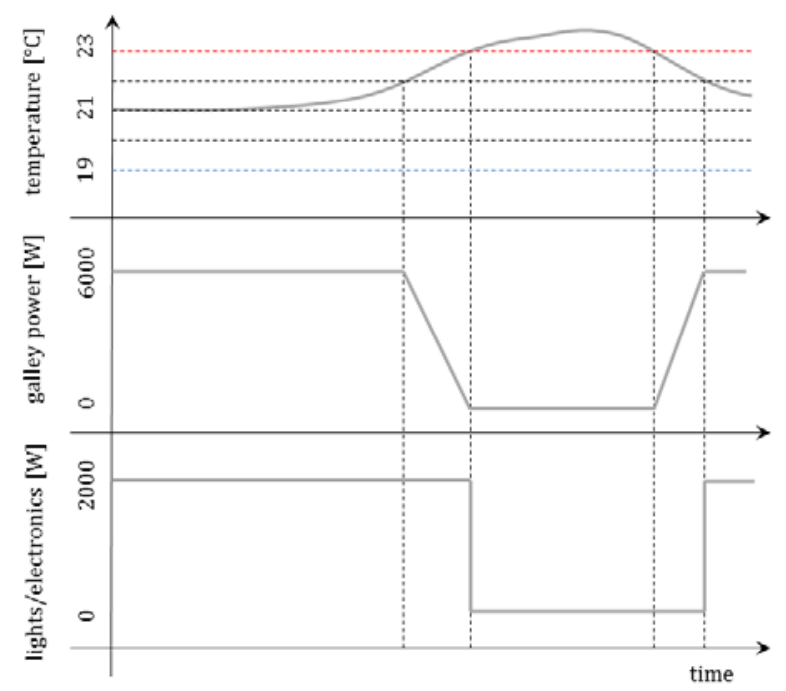

Figure 6: Reduction of thermal peak heat loads.

For this strategy, instead of modifying the ECS, the idea is to reduce some of the thermal loads inside the cabin in certain situations,

Page 4 of 6 thereby limiting the operational envelope of the ECS, and enabling smaller, lighter components.

Two requirements have to be fulfilled for this to occur. First, the thermal architecture has to be strained beyond its performance limits. At that point, the cabin temperature set point (plus some optional allowed temperature band) cannot be maintained at the current environment conditions. Second, there have to be thermal loads which can be switched off without endangering the safety of the passengers or cabin crew. Examples for this are the ovens in the galleys, or inflight entertainment.

This would of course imply that sizing cases would be modified according to these procedures. Sizing cases are static, an inclusion of these measures in the sizing cases would imply that the reduction of heat loads can potentially last for an unlimited amount of time. A treatment based on a probabilistic view could improve this situation, giving the strategy the character of an emergency load shedding mechanism.

\section{Strategy 3 - Reduce Electrical Peak Loads}

The reduction of electrical peak loads sounds promising by using the thermal inertia of the cabin and aircraft galley as done in $[10,11]$. Typically, the electrical system is being sized according to the sum of maximal power consumptions of single loads in each flight phase [15]. Nevertheless, the power consumption of loads is strongly fluctuating, causing the mean value of power to be provided to be much smaller than the maximal values. Hence, the electrical system is strongly oversized causing a huge system mass. Additionally, power peaks of loads do normally not appear at the same time of all loads and there are many loads like actuators that need this peak power only for some seconds. Electrical batteries and capacitors could deal with these power peaks, but a sufficient power and energy capability would add a lot of weight to the electrical system. Hence, there are normally no electrical storage elements in active use onboard an aircraft.

The thermal inertia of aircraft cabin and galley could be exploited in the same way as an electrical storage element while having an impressive performance. The entire galley can have a power consumption of up to $240 \mathrm{~kW}$, whereas the ECS may use electrical power of up to $500 \mathrm{~kW}$. Even though only a part of this power may be used for cooling and heating, one can assume like $100 \mathrm{~kW}$ for ECS and at least $50 \mathrm{~kW}$ for aircraft galley. The amount of exploitable energy that is "stored" in the galley can get up to $1.7 \mathrm{kWh}$ and 100 Wh for the cabin. To reach a similar performance, one would need a $1.8 \mathrm{kWh}$ battery or supercapacitor and a converter carrying $150 \mathrm{~kW}$. That could lead to a battery weight of $150 \mathrm{~kg}$ (due to power density), assuming an energy density of $100 \mathrm{Wh} / \mathrm{kg}$ and a power density of 1 $\mathrm{kW} / \mathrm{kg}$. In addition, the converter weights another $25 \mathrm{~kg}$ (assuming 6 $\mathrm{kW} / \mathrm{kg}$ for a DC/DC converter).

Whereas exploiting the galleys and ECS, one can only reduce the actual power consumption in case of an electrical overload first, until the physical state (e.g. the cabin and galley temperature) leaves a prescribed boundary. This enables, among others, the sizing of the electrical system with a more realistic worst case. Figure 7 illustrates two different sizings of engine generators. Firstly, a conservative sizing using the sum of maximum power consumptions per load is illustrated. Secondly a sizing with a realistic worst case approach using statistical data is shown. The illustrated reductions in system weight are massive. 


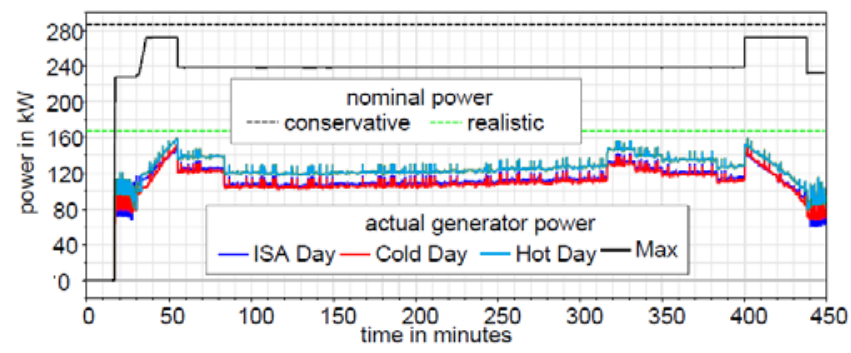

Figure 7: Comparison of conservative sizing of the electrical generators with an improved sizing based on statistical and model based data.

As long as the actual power consumption is below the assumed realistic power consumption, there is no exploitation of cabin and galley dynamics needed. Only, if a component fails or a load consumes much more than expected, overload situations may appear. Figure 8 illustrates such a situation, where one of the four engine generators fails.
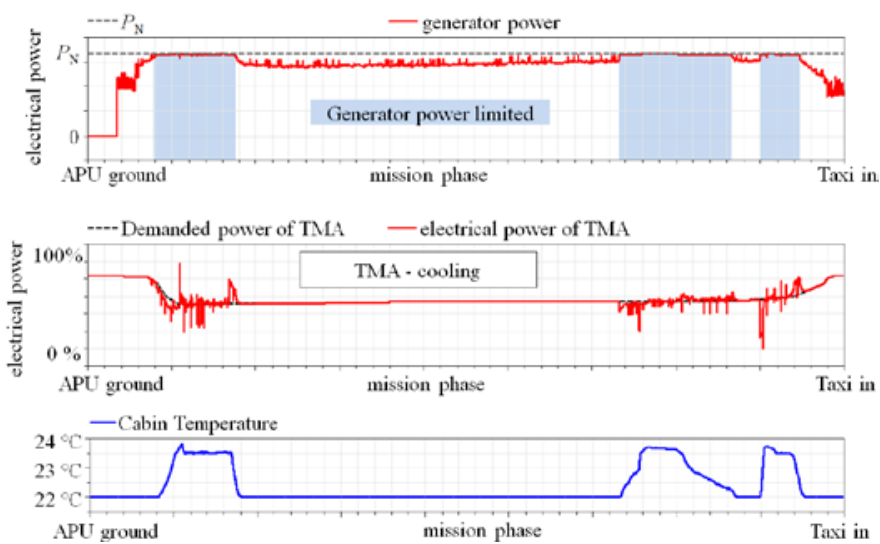

Figure 8. Using the cabin dynamics to increase load availability of the electrical system.

Here, the electrical power of the TMA (mainly ECS and vapor cycle) and the galley is reduced firstly in case of a generator overload. If the cabin temperature reaches $23.5^{\circ} \mathrm{C}$, the priority of the TMA cooling increases up to its maximum priority at $24{ }^{\circ} \mathrm{C}$ to stay below $24^{\circ} \mathrm{C}$. This means, that now other low priority loads needs to be reduced. But, the availability of these loads can be increased drastically even for this situation. There are many other cases, where the cabin and galley thermal storage can even take the entire power peak.

\section{Discussion and Comparison}

Having demonstrated that strategy 1 and 2 deliver only minor or even no further benefits while reducing comfort, strategy 3 is the best way to exploit the thermal inertia of the galley and the aircraft cabin. To quantify the benefit in fuel consumption or other emissions, we firstly need to identify the potential mass reduction of the electrical system. This is hard to determine in practice, since the mass reduction will follow from a combination of the statistical approach of sizing the network and the usage of the thermal dynamics to increase load availability. In [17] a combination of both leads to a mass reduction of $1400 \mathrm{~kg}$ for a fictive A330 MEA architecture using 540 VDC main bus. Using the DLR FlightDynamics Library [9], one can now calculate the impact of this mass reduction on fuel burn for a mission. For the selected mission from London to New York, we get a reduction of about $1.7 \%$ of fuel. The impact of the thermal storage will only be a part of this figure, but still significant. Nevertheless, values need to be calculated for concrete aircraft, electrical system architecture and mission. The investigation in this paper shall mainly show the best strategy rather than giving exact numbers.

\section{Conclusions}

In this paper, we explored three different exploitation strategies for the cabin dynamics. The first two strategies confined themselves to the thermal domain and could only result in minor advantages, if any at all. If one also accounts for the additional effort esp. regarding the safety-regulations, these two strategies seem hardly promising and are not further pursued.

The third strategy, however, exploits the fact that what might be regarded as rather small time-constant for a thermal system may also be regarded as very long time constant for an electrical system. Hence the thermal dynamics offer an excellent opportunity for temporary load reduction, which in turn enables a reduction of conservatism in sizing due to overall peak load reduction.

Strategy 3 has also the least impact on passenger comfort for normal operation. While strategy 1 would actually be applied on every single flight, the effects of strategy 3 would not be noticed in the vast majority of flights. Although conservatism is significantly reduced, the sizing of electrical systems is still done based on failure cases and still contains significant redundancy. For a normally operating airplane with all generators working, there is still enough excess power available and comfort will be prioritized over peak load reduction.

Our future work will hence focus on the interaction of ECS systems and galley ovens with the electrical system and on using the thermal dynamics as energy storage. For any optimization task within the thermal domain only, the cabin thermal dynamics do not seem to offer a sufficient optimization potential. Here we choose to continue the work detailed in [15] that focus on an optimal usage of ECS depending on the current flight conditions.

\section{References}

1. Clean Sky Joint Undertaking (CSJU), “ACARE and the environmental objectives," http://www.cleansky.eu/content/homepage/aviationenvironment/, March 2014.

2. Faleiro, L., "Beyond the More Electric Aircraft" AIAA Aerospace America (September): 35-40, 2005.

3. AbdElhafez, A. A., and Forsyth, A. J., "A review of more electric aircraft,” presented at 13th International Conference on Aerospace Sciences and Aviation Technology, ASAT- 13, 2009.

4. Sielemann, M.; Giese, T.; Oehler, B.; Gräber, M., “Optimization of an Unconventional Environmental Control System Architecture,” SAE International Journal of Aerospace 4(2): 1263-1275, 2011, doi:10.4271/2011-01-2691

5. Modelica Association, "Modelica and the Modelica Standard Library,” https://modelica.org/, March 2014.

6. Schlabe, D., Zimmer, D., "Model-Based Energy Management Functions for Aircraft Electrical Systems," SAE Technical Paper 96083, 2012, doi:10.4271/2012-01-2175. 
7. D. Schlabe and J. Lienig, "Model-based thermal management functions for aircraft systems,” in Proc. SAE 2014 Aerospace Systems and Technology Conf. (ASTC), SAE Technical Paper 2014-01-2203, Cincinnati, OH, September 2014.

8. Schlabe, D., Zimmer, D., "Energy Management of a System According to an Economic Market Model Approach,” U.S. Patent 020140058573 A1, February 27, 2014.

9. Looye, G., “The New DLR Flight Dynamics Library,” presented at 6th Modelica Conference, 2008.

10. W. Glahn, G. Dueser, A. Koenig, M. Finck, and J. Reitmann, "Intelligent power distribution management for an on-board galley of a transport vehicle such as an aircraft,” U.S. Patent 7,098,555 B2, 2006.

11. B. Waite, J. White, and W. Atkey, "Dynamic electrical load management,” U.S. Patent 2009/0 152942 A1, 2009.

12. D. Schlabe and J. Lienig, "Energy management of aircraft electrical systems - state of the art and further directions," in Electrical Systems for Aircraft, Railway and Ship Propulsion (ESARS), 2012, pp. 1-6.

13. Federal Aviation Administration. Airbus A320 Family, Master Minimum Equipment List.

14. Federal Aviation Administration. Federal aviation regulations $\S 25.831$ 'ventilation' last amended 1997

15. D. Schlabe and J. Lienig, "Model-based thermal management functions for aircraft systems,” in Proc. SAE 2014 Aerospace Systems and Technology Conf. (ASTC), SAE Technical Paper 2014-01-2203, Cincinnati, OH, September 2014.

16. T. Schroeter, B. H. Nya, and D. Schulz, "Potential analysis for the optimization of the electrical network of large modern civil and future single aisle aircraft and examples of the network capacity utilisation,” in Proc. Electrical Systems for Aircraft, Railway and Ship Propulsion (ESARS), 2010.

17. D. Schlabe, „Modellbasierte Entwicklung von

Energiemanagement-Methoden für Flugzeug-Energiesysteme“ PhD Thesis, TU Dresden, Fortschritt-Berichte VDI, 2015

\section{Contact Information}

Daniel Schlabe

Institute of System Dynamics and Control

DLR German Aerospace Center

Wessling, Germany

Email: daniel.schlabe@dlr.de

Dirk Zimmer

Institute of System Dynamics and Control

DLR German Aerospace Center

Wessling, Germany

Email: dirk.zimmer@dlr.de

Alexander Pollok

Institute of System Dynamics and Control

DLR German Aerospace Center

Wessling, Germany

Email: alexander.pollok@dlr.de

TMF

This work has previously received funding from the European Union's Seventh Framework Programme (FP7/2007-2013) for the Clean Sky Joint Technology Initiative under grant agreement $n^{\circ}$ CSJU-GAN-SGO-2008-00.

The work is receiving funding from European Union’s Horizon 2020 for the Clean Sky 2 Joint Technology Initiative under grant agreement H2020-CS2-CFP03-2016-01 GAN 737792.

\section{Definitions/Abbreviations}

\begin{tabular}{ll} 
ACM & Air Cycle Machine \\
ECS & $\begin{array}{l}\text { Environmental Control } \\
\text { System }\end{array}$ \\
ELM & Electrical Load Management \\
EMF & Energy Management \\
& Function \\
MEA & More Electric Aircraft \\
RAC & Ram Air Channel \\
SFC & Specific Fuel Consumption \\
TF & Trade Factor \\
TMA & Thermal Management \\
& Architecture \\
TMF & Thermal Management \\
VAC & Function \\
& Vapor Cycle \\
\hline
\end{tabular}

